\title{
Application of Hybrid Hardware-Software Simulator for Automatic Voltage Regulators Setting
}

\author{
Alisher Askarov ${ }^{1, a)}$, Mikhail Andreev ${ }^{1, b)}$ and Irina Chesnokova ${ }^{1, c)}$ \\ ${ }^{1}$ National Research Tomsk Polytechnic University, 634050 Tomsk, Russia. \\ ${ }^{a)}$ Corresponding author: aba7@tpu.ru \\ b)andreevmv@tpu.ru \\ c)taksimo@tpu.ru
}

\begin{abstract}
Today mathematical simulation is practically sole method, with no alternative, for obtaining comprehensive and reliable information about regimes and processes in electrical power systems. This is due to the impossibility of making field tests in real EPS, and significant limits of physical models. Therefore, according to official standards and regulatory documents of JSC "SO UPS", the development of the hardware-software simulators for real-time power system simulation with the purpose of automatic voltage regulators setting and certification is the most urgent issue. This paper proposes the Hybrid Real-Time Power System Simulator usage as the solution. The performed studies and tests (partially demonstrated in the article) show the possibility of such simulator usage for the stated aims.
\end{abstract}

\section{INTRODUCTION}

Synchronous generators are the fundamental principle for the operation of any power system - they generate electricity, which is then transmitted to the consumers. Consequently, the normal generator operation ensures stable operation of a power plant and an electric power system (EPS) as a whole, in which everything is interconnected and the development of accidents often occurs in a cascade.

The main purpose of automatic voltage regulators (AVR) is to maintain the generator parameters within the prescribed limits. However, ineffective or erroneous AVR setting can lead to large-scale accidents associated with the blackouts, EPS islanding and significant material damage [1-4].

\section{BACKGROUND}

In the Russian Federation, the standards of JSC "SO UPS" [5] define the requirements for the AVR devices and their settings. According to these documents, validation of new AVR parameters setting is carried out in two ways via:

1. EPS physical model - electrical machines, power transformers, etc. are represented by similar equipment in small scale;

2. EPS mathematical model using hardware-software real-time power system simulators (HPS).

At the same time, at present, AVR setting and certification are still carried out on the EPS physical model with the tendency towards HPS usage. In the JSC "SO UPS" standard [5], one of such simulators is the RTDS (RTDS Technologies Inc., Canada), which has a high cost, as well as being developed and manufactured only in Canada. These facts raise the question about the import substitution in this area. 


\section{PROPOSED SOLUTION}

The design of the first hybrid software and hardware simulator for AVR setting and certification is proposed to be carried out on the basis of the Hybrid Real-Time Power System Simulator (HRTSim). The HRTSim is based on a hybrid approach for EPS simulation and developed by research group of "Research \& Development Laboratory for Electrical Power System Simulation" at the National Research Tomsk Polytechnic University. Such power system simulator represents a multiprocessor system that combine physical, analog and digital simulation. There are some HRTSim key advantages over the currently widely used digital power system simulators:

1. Modes and processes decomposition is excluded;

2. No limits for simulation time interval;

3. High simulation accuracy which is limited only by the instrumental error and depends on the component modules;

4. The continuous methodically accurate real-time solution of the three-phase mathematical models of different EPS elements is provided;

5. There are no limits on the simulated EPS size and the mathematical model detalization level (for example, generator model, regulators models, etc.).

This simulator meet the requirements of the Russian Federation documents and standards. The HRTSim distinctive features, properties and capabilities allow it to be used for a wide range of issues, for example, relay protection setting, VSC HVDC simulation, etc. [6-8].

\section{RESEARCH RESULTS AND DISCUSSION}

The aim of the article is to perform experiments for validation of the AVR mathematical model (Fig. 1) used in HRTSim for compliance with the requirements of the JSC "SO UPS" standard via HPS - RTDS, which has a sufficiently high accuracy and speed of calculations, as well as the internationally recognized and widely used for EPS simulation. The structural scheme of the AVR mathematical model is presented in Fig. 1. Such model is based on the analysis of AVR structure, which are widely used in Russian power systems, as well as known variants of their modeling, and allows to take into account the relevant parts and parameters for the accurate simulation of the AVR devices and also excitation systems (after " $E_{q e}$ ").

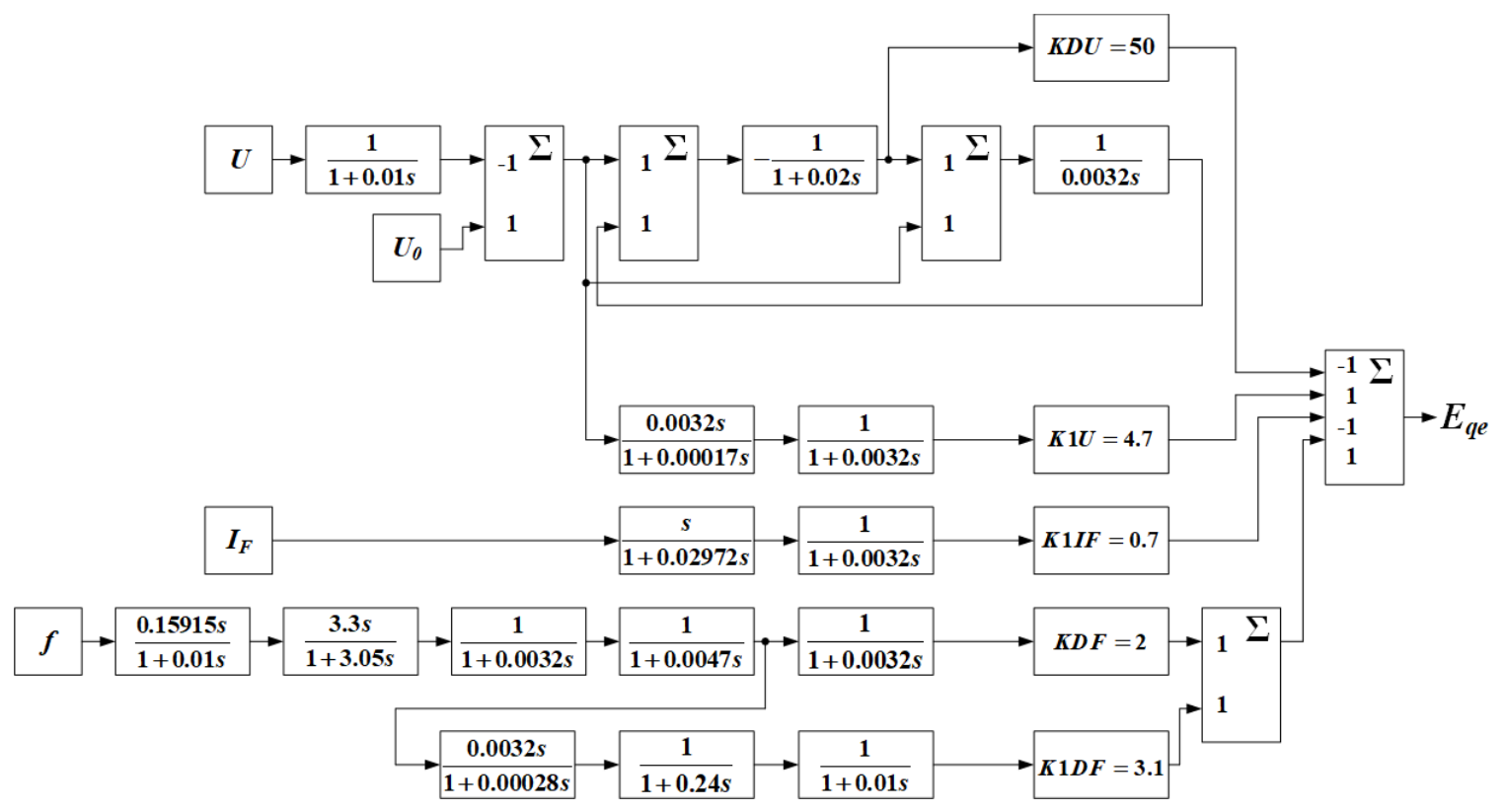

FIGURE 1. Experimental AVR mathematical model

The basic scheme for the studies was a part of the Tomsk region power system (Fig. 2). The normal steady-state mode was reproduced in HRTSim and RTDS via SCADA control measurements. The generator with a rated capacity 
of $140 \mathrm{MW}$, located at one of the Tomsk region power stations, with the AVR model, presented above, was used as the investigated generator. The validation of the AVR correct operation, modeled in HRTSim and RTDS, was carried out via test disturbances presented in [5].

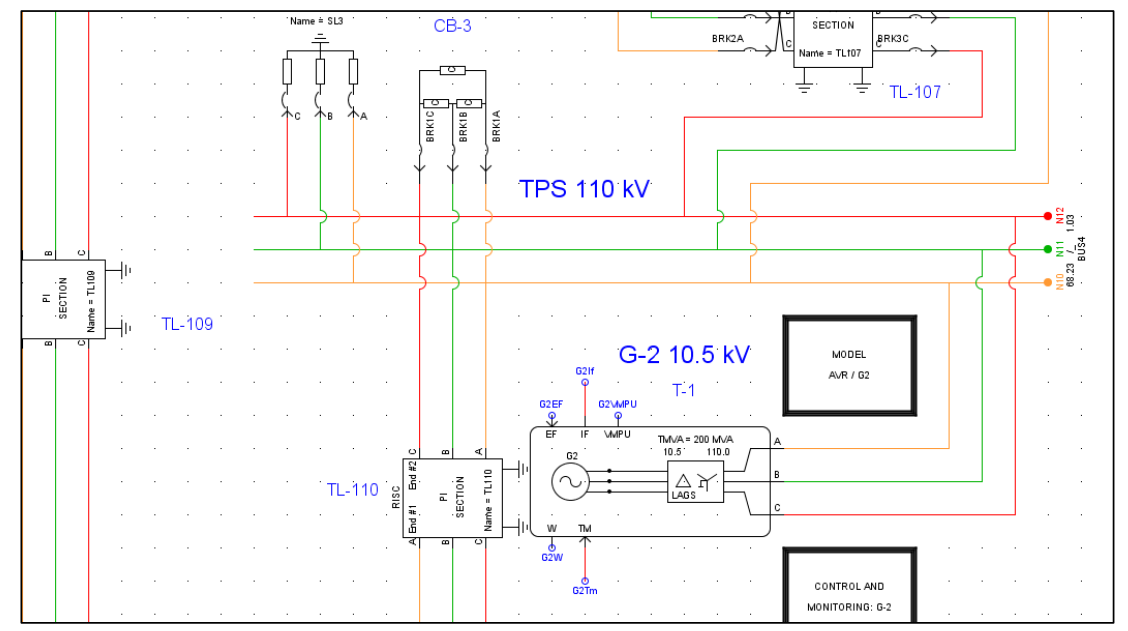

FIGURE 2. The three-phase view of a part of the simulated EPS in RTDS

In this paper, as an example, the results of the following test disturbance are presented: a step-like change in the EPS reactive power balance via capacitor banks connection (with a total capacity of $85 \mathrm{MVAr}$ ) to $110 \mathrm{kV}$ buses at the power plant with the investigated generator (Fig. 3). The point of this experiment is that in the case of the correct AVR operation, when the reactive power balance changes due to the connection of an additional capacity on the power station buses and the subsequent disconnection of this capacity (after $5 \mathrm{sec}$ ), at the initial time an increase in the voltage on the power station buses and a decrease in the excitation current to the minimum permitted value should occur what ensures the operation of the underexcitation limiter (UEL) [9, 10]. The UEL does not allow a further decrease in excitation level, which can lead to a loss of generator stability and EPS stability in general. Such operation in the underexcitation-zone should not be attended by the excitation current fluctuations and, as a consequence, the voltage fluctuations at the generator terminals, and, when the additional capacity is disconnected, the parameters should be restored to rated values as soon as possible.
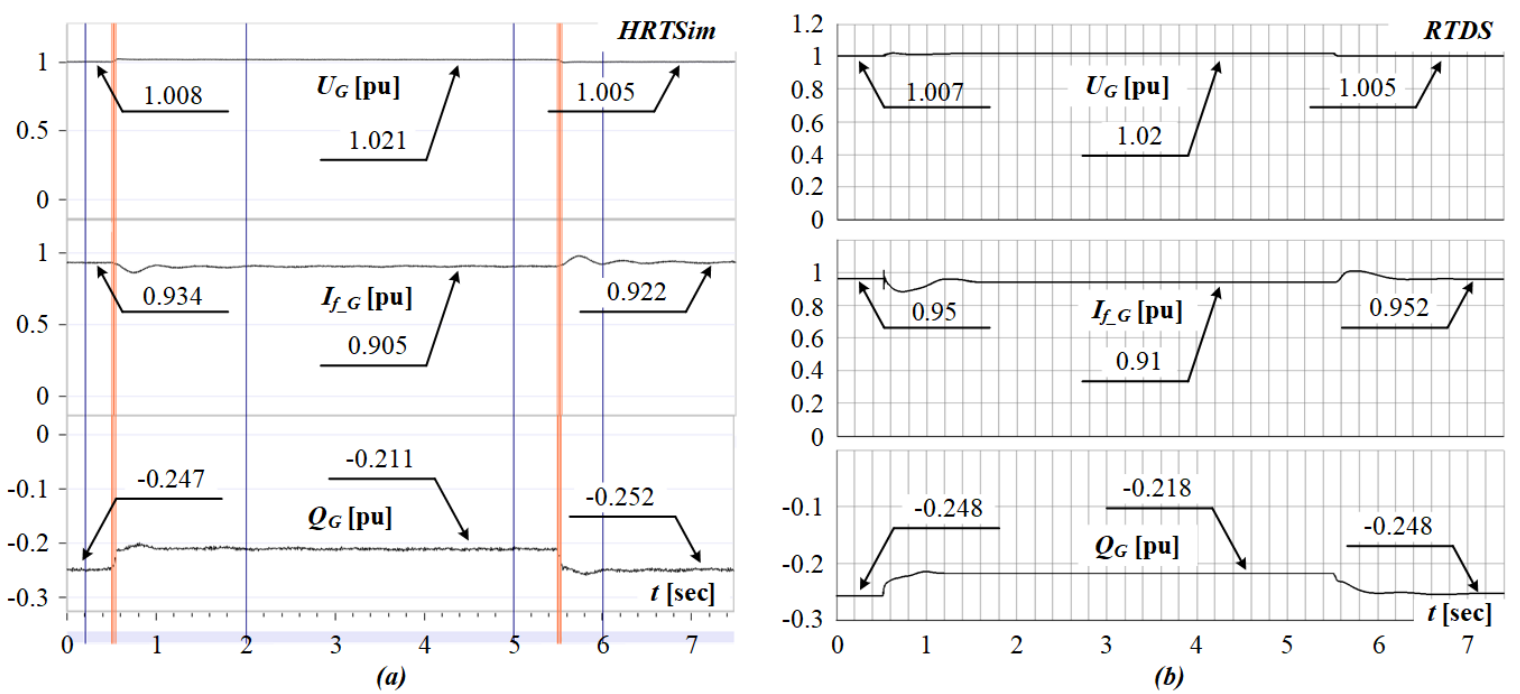

FIGURE 3. The oscillograms of the AVR model operation received via HRTSim (a) and RTDS (b)

The obtained oscillograms in Fig. 3 show that the operation of the tested AVR model is not attended by the excitation current fluctuations and similar in both simulators. The absolute error is less than $5 \%$. 


\section{CONCLUSION}

Further work is focused on the development of hardware-software interface for interoperation between HRTSim and AVR for setting and certification used in power stations digital excitation regulators. Such interface would allow

to test and setup AVR under conditions close to actual operation. The developed means in the future has a competitive advantage in terms of cost in comparison with existing analogues, due to the lower unit cost of the modeled equipment. Among other things, the HRTSim is focused on Russian models of equipment, regulation systems and methods for EPS simulation, unlike existing analogues, adapted for international standards and regulatory documents.

\section{ACKNOWLEDGMENTS}

The reported study was funded by Ministry of Science and Higher Education of Russian Federation, according to the Agreement No. 075-02-2018-271 "Investigation of the influence of the spectrum of processes in electric power systems with a significant share of distributed generation and renewable energy sources on the functioning of relay protection devices and the development of a methodology for its adequate setting up".

\section{REFERENCES}

1. S. K. Samanta and C. K. Chanda, 2017 IEEE Calcutta Conference (CALCON), (IEEE, Kolkata, 2017), pp. 241247.

2. V.A. Kuzmichev, E.V. Konovalova, S. N. Sakharov and A.Yu. Zakharenkov, New Russ. Electr. Power Eng. 7, 5-10 (2014).

3. S. O. Smirnov and M. I. Uspenskii, Proc. Komi Sci. Cent. Ural Div. Russ. Acad. Sci. 1(9), 68-77 (2012).

4. A. Atputharajah and T. K. Saha, 2009 International Conference on Industrial and Information Systems (ICIIS), (IEEE, Sri Lanka, 2009), pp. 460-465.

5. STO 59012820.29.160.20.001-2012. Requirements for excitation systems and automatic excitation regulators of forced control of synchronous generators, (Publishing Standards, Moscow, 2012)

6. A. A. Suvorov, A. S. Gusev, A. O. Sulaymanov and O. V. Suslova, MATEC Web Conf. 91, 1-4 (2017).

7. R. A. Ufa, A. S. Vasiliev, A. S. Gusev and A. A. Suvorov, Proceedings of 11 th International Forum on Strategic Technology (IFOST), Novosibirsk, 2016, edited by F. Byk et. al. (Novosibirsk State Technical University, Novosibirsk, Russia, 2016), pp.113-117.

8. N. Y. Ruban, A. O. Sulaymanov, R. A. Ufa and I. A. Razzhivin, MATEC Web Conf. 91, 1-4 (2017).

9. P. Kundur, Power System Stability and Control (McGraw-Hill, New York, USA, 1993), p. 1199.

10. P. M. Anderson and A. A. Fouad, Power System Control and Stability (John Wiley \& Sons, Hoboken, 2003), p. 689. 